Resenha: VERDURE-MARY, Anne. Drame et pensée: la place du théâtre dans l'œuvre de Gabriel Marcel.

\title{
DRAMA E PENSAMENTO EM GABRIEL MARCEL
}

VERDURE-MARY, Anne. Drame et pensée: la place du théâtre dans l'œuvre de Gabriel Marcel. Paris: Honoré Champion, 2015, 520p [Collection Poétiques et esthétiques XXe-XXIe siècle, $\left.\mathrm{n}^{\circ} 19\right]$.

Claudinei Aparecido de Freitas da Silva*

No circuito da tradição fenomenológico-existencial, a produção dramatúrgica de Gabriel Marcel (1889-1973) marca, indelevelmente, uma posição singular. É o próprio autor que avalia sua obra como que indissociável de um projeto que, já em fins dos anos 1920, se matura sob o signo de uma "hiperfenomenologia", isto é, a radicalização da fenomenologia husserliana e de todo idealismo crítico. É, em meio, pois, a esse contexto programático que se encampa a tarefa de uma "filosofia concreta"; tarefa essa que, em termos marcelianos, se radica a partir de uma experiência fundamental: o "mistério do ser". Nessa perspectiva, o teatro não apenas teria ocupado um plano mais imediato de interesses, mas, igualmente, exercido um papel decisivo como impulso ao próprio trabalho filosófico heuristicamente em curso de Marcel. Frente a isso, é ele que sempre fez questão de se esclarecer, quanto ao adjetivo corrente de "filósofo-dramaturgo". Há de se ter cuidado com relação ao traço dessa união, assim precisa, pois não se trata absolutamente de duas atividades justapostas. Fato é que, em versão marceliana, drama e pensamento se confundem como duas criações inseparáveis, ou seja, como dois gestos profundamente recíprocos.

É revisitando essa aliança indissolúvel que, após várias décadas, publicações de alto nível começam a circular não só junto à comunidade filosófica, stricto sensu, mas a um meio cultural bem diversificado. O biênio 2014/2015, por exemplo, constitui uma prova inconteste disso. Em 2014, a Albo Versorio, de Milão, brinda o público com Ontologia e dramma: Gabriel Marcel e Jean-Paul Sartre a confronto de autoria de Luca Aloi. Com prefácio de Franco Riva, o livro prima por um meticuloso balanço circunscrito por Aloi entre as obras de

\footnotetext{
* Professor dos Cursos de Graduação e de Pós-Graduação (Stricto Sensu) em Filosofia da UNIOESTE - Campus Toledo com Estágio Pós-Doutoral pela Université Paris 1 - Panthéon-Sorbonne (2011/2012). Escreveu " $A$ carnalidade da reflexão: ipseidade e alteridade em Merleau-Ponty" (São Leopoldo, RS, Nova Harmonia, 2009) e "A natureza primordial: Merleau-Ponty e o 'logos do mundo estético"” (Cascavel, PR, Edunioeste, 2010). Organizou "Encarnação e transcendência: Gabriel Marcel, 40 anos depois" (Cascavel, PR, Edunioeste, 2013), "Merleau-Ponty em Florianópolis" (Porto Alegre, FI, 2015) e "Kurt Goldstein: psiquiatria e fenomenologia" (Cascavel, PR, Edunioeste, 2015). Endereço para contato: Rua da Faculdade, 645 - CEP: 85903.000 - Toledo (PR). Fone: (45) 3379 7127. E-mail: cafsilva@uol.com.br.
} 
Gabriel Marcel e Jean-Paul Sartre, à luz, é claro, do teatro. Isso, no entanto, não é tudo! A locomotiva editorial segue a todo vapor. Mal fecha o ano e, em janeiro de 2015, outra produção de peso vem a público: Drame et pensée: la place du théâtre dans l'œuvre de Gabriel Marcel, pela Honoré Champion, de Paris. Contando com 520 páginas, é mais um trabalho de fôlego, ou seja, de encher a vista! Também pudera: ele é assinado por ninguém mais que Anne Verdure-Mary. Quem, afinal, é ela?

Uma breve síntese de seu currículo: é arquivista paleógrafa, curadora de várias exposições como a de "Boris Vian" (outubro de 2011/janeiro de 2012) e de "Edmond Jabès, l'exil en partage" (maio-junho/2012) na Bibliothèque Nationale de France (BNF). É ainda conservadora do Departamento de Manuscritos da própria BNF, sendo responsável pelos fundos de vários escritores contemporâneos como Jean-Paul Sartre, Simone de Beauvoir, Boris Vian, Jean Grenier, Edmond Jabès, entre outros. Anne Mary tem também publicado inúmeros artigos sobre a obra de Gabriel Marcel. Drame et pensée, resultado de sua tese em literatura francesa, defendida em 2008, na Sorbonne, inscreve-se, seguramente, como o grande marco até agora na carreira. Para que o leitor disso se certifique, adentremos, mesmo que, de relance, no espírito geral do livro.

Sua estrutura compõe-se de três partes essenciais, cada qual subdividida em quatro capítulos. A primeira parte põe na arena do debate, o confronto entre teatro e filosofia, retratando, sucessivamente, i) a vocação teatral de Marcel; ii) sua concepção teóricodramatúrgica; iii) a própria realização dramática e iv) os traços criativos da obra, via os manuscritos do filósofo. A segunda parte reporta-se às noções dramáticas no coração da obra filosófica, ou seja, o itinerário do autor em direção à ontologia. Nesse roteiro, compreendemse, i) a relação entre presença e mistério; ii) a encarnação, o ato e a situação; iii) o teatro como lugar de interrogação filosófica e da esperança e iv) o teatro como experimentação filosófica. Por fim, a terceira parte situa propriamente a questão do teatro e seu papel mediador junto à experiência intersubjetiva. Daí o desdobramento dos capítulos: i) a abertura sobre a esperança e a religião; ii) a dimensão socrática do diálogo; iii) a experiência da comunhão e iv) os três modos de comunhão: o teatro, a música e a prece. Além da vasta literatura bibliográfica, o projeto encerra com dois anexos (biografia e resumo das peças de Marcel) acompanhados, ainda, de índice onomástico. Por meio dessa estrutura mínima, o leitor tem, em primeira mão, uma visão mais ampla do contributo considerável de Verdure-Mary. O que a autora põe, em cena, é um retrato da produção marceliana que guarda uma unidade interna, inextrincável e significativamente pujante. O minucioso estudo das peças teatrais de Marcel e suas críticas 
Resenha: VERDURE-MARY, Anne. Drame et pensée: la place du théâtre dans l'œuvre de Gabriel Marcel.

dramáticas, bem como de seus textos filosóficos, permite como que Mary esboce, com elegante primor, o contorno de uma obra coerente em que cada escrito, qualquer que seja o gênero, reclama o outro, numa só articulação e profusão. É, fundamentalmente, esse "todo indivisível”, para empregar a bela expressão de Schelling, um dos autores diletos do pensador francês, que Mary capta a cada instante sob a lente desse notável trabalho. Trabalho este que, diga-se de passagem, por si só, credita, insofismavelmente, um imenso e valoroso serviço prestado à fenomenologia e sua inserção no debate mais amplo da cultura científica e da arte.

Marcel jamais concebe seu teatro à revelia de um dado contexto. $\mathrm{O}$ drama é sempre situacional, ou seja, pressupõe um gesto de engajamento desinstalando completamente o espectador. Este é, na verdade, deslocado de sua zona de conforto: a cômoda posição em que ocupar uma poltrona no auditório se reduz, passivamente, a assistir um espetáculo. Ora, participamos de uma só realidade que nos habita e transcende. Isso é a encarnação, quer dizer: a condição inalienável pela qual o pensamento se exerce, embebido no concreto, mergulhado na finitude. É o momento em que "a experiência transmuta-se em pensamento" (Marcel, Essai de philosophie concrète, Paris: Gallimard, 1999, p. 43). Como prefacia Marcel em La dignité humaine (Paris, Aubier, 1964, p. 9-10): “se a expressão dramática é, por excelência, existencial [...] é porque é no drama que o pensamento se atualiza, tornando manifesto, não apenas para o público ao qual esse drama se destina, mas para o próprio filósofo existencial". Trata-se de um sentimento que se revive intensamente: "a obra dramática [...] é o que vem irrigar o meu pensamento especulativo" (Idem, op. cit., p. 18). Marcel ainda tributa sua vocação dramatúrgica à memória de seu pai, administrador da Academia de Belas Artes, de Paris, que, segundo, o filósofo, era um homem de cultura universal. É daí que, uma vez iniciado na arte, surge, no jovem Marcel, "o amor pelo teatro". Não é demais registrar, em função disso, que a sua intuição musical como compositor brota dessa mesma inspiração. A propósito, dirá ele, certa vez: “A música aparece assim como a expressão cada vez mais sensível e suprassensível dessa intersubjetividade que revela, no plano da reflexão filosófica, a descoberta do tu e do nós concreto" (Idem, op. cit., p. 74).

É na obra de arte (especialmente na composição dramática) que o pensamento se realiza, in concreto. Para além da árida reflexão abstrata, o filosofar incorpora tal qual, na Poiética, a catarse do trágico, do épico e do cômico. Ao mesmo tempo, é preciso instruir-se da lição tão bem ilustrada no Sofista, de que a relação entre o "mesmo" e o "outro" é, antes de tudo, uma relação dialógica. A dialética, aí, se faz arte. Essa é, pois, a marca da atitude neossocrática avocada por Marcel não apenas nos ensaios filosóficos que escreve, mas em sua 
produção dramática. Trata-se, enfim, de refutar todo juízo disjuntivo entre sujeito e objeto, ator e espectador. O drama encarna, admiravelmente, outro nível de intencionalidade: a intimidade carnal de seus personagens, revivendo, hic et nunc, o mistério da intersubjetividade. Esse mistério põe a toda prova a fundação arquimédica do argumento solipsista como um ideal que se desconstrói, radicalmente, em face do "inesgotável concreto", ou seja, a própria experiência do real. É sob esse escopo que a obra de Marcel - heurística, por excelência, - encontra no experimento cênico um privilegiado recurso hiperfenomenológico. O ser, de uma vez por todas, entra em mise-en-scène: torna-se presença viva. Nessa abertura ou reconhecimento, a distinção entre o ontológico e o ôntico (o ser e o aparecer) não passa de um expediente formal, desprovido, a priori, pois, de sentido.

É nesse pano de fundo que o livro de Anne Mary assume um fulgor literário à altura do que realmente se propõe! Ao lado do trabalho de Aloi, é mais um evento digno de nota que fecha um próspero biênio editorial. Com isso, deixa então a sua marca registrada como referência não só a quem se dedica, em particular, à obra e o pensamento marcelianos, mas à boa cultura filosófica em geral. É projetando tal raio de abrangência que Drame et pensée já pode inserir-se, ao lado de tantos outros, como um clássico em meio à fortuna crítica desse insigne mestre que fora Marcel. Celebremos! Brindemos! Tintim ao leitor! 